\title{
The significance of dynamics of ST segment changes when assessing the effectiveness of mechanical reperfusion of the myocardium in hyperglycaemic patients with acute myocardial infarction with persistent ST-segment elevation
}

\author{
Marek Andres $^{1 *}$, Jacek Legutko ${ }^{1}$, Ewa Konduracka ${ }^{2}$, Maciej Małecki ${ }^{3}$ Janusz Andres $^{4}$ and Krzysztof Ż mudka $^{1}$ \\ ${ }^{1}$ Department of Interventional Cardiology, John Paul II Hospital, Krakow, Poland \\ ${ }^{2}$ Department of Coronary Heart Disease, John Paul II Hospital, Krakow, Poland \\ ${ }^{3}$ Department of Metabolic Diseases, Jagiellonian University Medical College, Krakow, Poland \\ ${ }^{4}$ Department of Anesthesiology and Intensive Care Medicine, Jagiellonian University Medical College, Krakow, Poland
}

\begin{abstract}
Background: The coexistence of coronary heart disease and consequently acute myocardial infarction with persistent ST-segment elevation (STEMI) and glucose metabolism disorders is well known. Still, glucose metabolism disorders in the STEMI population are not fully understood. We know that diabetes mellitus (DM) is a factor disabling the function of microcirculation, which in turn may affect the outcome of a coronary intervention. The aim of this study was to evaluate the dynamics of ST-segment changes in ECG (electrocardiogram) in STEMI (ST-segment elevation myocardial infarction) patients with co-existing hyperglycaemia compared to those with normoglycemia treated with percutaneous coronary intervention (PCI), as well as to determine this parameter in the assessment of reperfusion effectiveness.
\end{abstract}

Methods: The study included 92 patients with the diagnosis of STEMI enrolled in the PCI treatment and was divided into groups based on the glucose levels on admission (reactive hyperglycaemia): a group with higher glucose levels on admission (Glc $\geq 7.8 \mathrm{mmol} / \mathrm{L}$, $\mathrm{n}=46$ ), a group with lower glucose levels on admission (Glc $<7.8 \mathrm{mmol} / \mathrm{L}, \mathrm{n}=46)$ and into groups based on the concentration of HbA1c : a group with a lower HbA1c level (<6.5\% (48 mmol/mol), $\mathrm{n}=71)$ and a group with a higher level $(\geq 6.5 \%, \mathrm{n}=21)$.

Results: On admission there were no significant differences in terms of clinical characteristics between the groups of patients with normoglycemia and reactive hyperglycaemia. After PCI the patients with normoglycemia had significantly higher ( $\mathrm{p}=0.021)$ dynamics of changes in the resolution of ST-segment elevation in ECG expressed in an indicator of sum STR (resolution of ST elevation). A degree of resolution of ST elevation in ECG was significantly (p=0.021) dependent on the level of blood glucose - the higher the blood glucose level, the weaker resolution. The patients with the glucose levels $\geq 7.8 \mathrm{mmol} / \mathrm{L}$ had significantly higher levels of $\mathrm{CK}$ and $\mathrm{CK}-\mathrm{MB}$ during the first 48 hours of hospitalization. There was a statistically significant difference in the mean length of hospitalization between individuals from the group with lower and higher blood glucose levels on admission ( $p=0.028$ ). A 4 -month follow-up revealed no significant difference in the incidence of $\mathrm{MACE}$ in the study groups ( $\mathrm{p}=0.063$ ). A 4-year follow-up of patients with higher levels of blood glucose on admission showed a higher incidence of MACE ( $\mathrm{p}=0.01$ ).

The patients with $\mathrm{HbA} 1 \mathrm{c} \geq 6.5 \%$ were older $(\mathrm{p}=0.004)$, had a greater BMI $>30 \mathrm{~kg} / \mathrm{m}^{2}(\mathrm{p}=0.019)$ and the lower ejection fraction of the left ventricle ( $\mathrm{p}=0.003$ ) compared to those with the HbA1c levels $<6.5 \%$. The incidence of MACE in 4-month and 4-year follow-up was comparable in the study population.

Conclusions: Myocardial reperfusion after primary angioplasty in acute myocardial infarction, which is determined by the degree of resolution of ST elevation in ECG, depends on the state of the glucose metabolism. The dynamics of changes in the ST-segment in ECG, taken immediately after PCI, is lower in patients with reactive hyperglycaemia.

\section{Introduction}

Carbohydrate metabolism disorders in patients with cardiovascular disease are recognized throughout the world and the number of glucose metabolism disorders in the population is rising steadily [1]. The majority of emergency patients admitted to cardiology wards have elevated blood glucose levels [2-5]. It is important to remember that a significant number of hospitalized patients had earlier been diagnosed as diabetic or pre-diabetic [6,7]. Systemic response to stress in the form of stress hyperglycaemia affects between $20 \%$ to $50 \%$ of patients with acute myocardial infarction and the considerable disparity is a consequence of different criteria used to determine the venous blood glucose level [8-11]. Despite this association between the degree of hyperglycaemia and poor clinical outcomes, there are few data demonstrating causation [12]. The question which the study endeavoured to answer is as follows:

${ }^{*}$ Correspondence to: Marek Andres, Department of Interventional Cardiology, John Paul II Hospital, Krakow, Poland, E-mail: marekandres@gmail.com

Key words: Acute myocardial infarction with persistent ST-segment elevation, reactive hyperglycaemia, glycated hemoglobin, myocardial reperfusion

Received: January 25, 2020; Accepted: February 06, 2020; Published: February 17,2020 
Andres M (2020) The significance of dynamics of ST segment changes when assessing the effectiveness of mechanical reperfusion of the myocardium in hyperglycaemic patients with acute myocardial infarction with persistent ST-segment elevation

is the final outcome of a PCI procedure only affected by a permanently elevated blood glucose level, estimated according to the concentration of glycated haemoglobin, or does reactive hyperglycaemia, which is part of the adaptive metabolic response to stress resulting from developing myocardial infarction, disturb microcirculation? It was shown that a high blood glucose level on admission to hospital has a significant impact on the dynamics of changes in ECG recordings, especially directly after coronary angioplasty. At the same time, it highlights the important role of sum STR indicator, especially as it translates into an unfavourable prognosis.

\section{Material and Methods}

Total 92 patients of first attack of acute myocardial infarction (STEMI) included considering inclusion and exclusion criteria diagnosed and qualifying for invasive treatment took part in the observational, prospective study with ethic approval from local ethical research committee. The study period lasted for 3 years (2014-2016) at the Department of Cardiology of Intervention at the John Paul II Hospital in Krakow. Inclusion criteria used by study were as follows: ST-elevation myocardial, defined as new ST-segment elevation $\geq 1 \mathrm{~mm}$ in $\geq 2$ contiguous leads, primary PCI within 24 hours of symptom onset. Exclusion criteria used by study were as follows: cardiogenic shock or pulmonary oedema (class III or IV according to Killip -Kimball) at the time of admission, history of diabetes, myocardial infarction of the same location in the past, coronary artery bypass surgery in the past, presence of left bundle branch block (LBBB) or active pacemaker rhythm, condition after sudden cardiac arrest and resuscitation, patient after prior fibrinolytic treatment. The patient population was divided into groups depending on their blood glucose level on admission (reactive hyperglycaemia) or the concentration of HbAlc: a group with an elevated glucose level on admission (Glc $\geq$ $7.8 \mathrm{mmol} / \mathrm{L}, \mathrm{n}=46$ ), a group with a lower glucose level on admission (Glc $<7.8 \mathrm{mmol} / \mathrm{L}, \mathrm{n}=46$ ), as well as a group with a lower HbA1c level $(<6.5 \%(48 \mathrm{mmol} / \mathrm{mol}), \mathrm{n}=71)$ and a group with a higher level $(\geq 6.5 \%$, $\mathrm{n}=21$ ). The degree of myocardial reperfusion was assessed in all patients based on the resolution of the ST segment elevation recorded in an electrocardiogram (sum STR at 0 and 60 minutes as well as 24 hours following the procedure) as well as on the basis of an angiographic examination (TIMI scale). The electrocardiography analysis involved the use of the classical and universally applied ECG recording indicator - the sum STR. The sum STR is expressed in percentage terms as the difference between the sums of ST segment elevation in an electrocardiogram prior to and following revascularization measured $20 \mathrm{~ms}$ from point $\mathrm{J}$ in leads connected with the myocardial infarction area $[13,14]$. In the present study complete resolution of ST segment elevation, expressed as sum STR $>70 \%$, was confirmed in successive time periods in an increasing number of patients in all the groups. Simultaneously, in accordance with predictions, incidences of ST segment elevation resolution, expressed as the sum STR indicator $<30 \%$, declined in each successive measurement. The extent of any myocardial injury was determined by the concentration of necrotic enzymes in the heart muscle - the creatine kinase $(\mathrm{CK})$ and creatine kinase $\mathrm{MB}$ fraction (CKMB) levels at 0 and 90 minutes, and then at 8,16,24 and 48 hours following the patient's admission to hospital. Echocardiograms were taken of all patients. These assessed left ventricular fraction both during hospitalization as well as 4 months after hospital discharge. The prognosis in the short-term and long-term follow-ups was determined according to the frequency of major adverse cardiovascular events
(MACE) defined as the composite of total death, myocardial infarction, coronary revascularization, stroke, and hospitalization because of heart failure during in-hospital observation and at 4-month and 4-year follow-ups.

Quantitative traits were characterized by specifying the mean and standard deviation, while qualitative traits by numerical and percentage distribution. The average values of quantitative traits were compared using Student's t test, Mann-Whitney test or Welch test. The relationship of two qualitative characteristics was verified based on the chi-square test or Fisher's exact test. The results were considered statistically significant when the calculated level of probability p did not exceed the level of significance $\alpha=0.05$. The calculations were made using the software R.

\section{Results}

This is a study of 92 individuals aged 32-87 years who had a first acute myocardial infarction. Men dominated in the analysed population (76, which constituted $82.6 \%$ of the whole group). There was no statistically significant relationship between gender and glucose on admission ( $\mathrm{p}=0.582)$. Analysing the group in terms of age, it was noticed that glucose levels $\geq 7.8 \mathrm{mmol} / \mathrm{l}$ were more common in the elderly $(\mathrm{p}=0,1637)$. Both groups were also similar in the presence of atherosclerosis risk factors that the patient was aware of and mentioned during the physical examination at admission. No significant differences in clinical assessments were observed between patients with lower glucose levels (Glc $<7.8 \mathrm{mmol} / \mathrm{L}$ ) and patients with reactive hyperglycaemia on admission to hospital (Table 1). A significantly greater $(\mathrm{p}=0.021)$ dynamic in the resolution of ST segment elevation in an electrocardiogram, expressed as sum STR, was observed only immediately after a PCI procedure in patients with normoglycemia determined on admission to hospital. The degree of ST segment elevation resolution in the ECG recording depended to a significant extent $(\mathrm{p}=0.021)$ on the blood glucose level on admission - the higher the glycemia the weaker the resolution of the ST segment (Figure 1). Significantly higher CK and CK-MB levels were noted in patients with blood glucose $\geq 7.8 \mathrm{mmol} / \mathrm{L}$ measured during the first 48 hours of hospitalization. An analysis of TIMI scores revealed no differences between the groups either prior to PCI ( $\mathrm{p}=0.638$ ) or after PCI $(p=0.372)$. This was also the case with the Rentrop scale $(\mathrm{p}=0.673)$. A statistically significant difference in mean hospital stay was observed between patients with lower and higher blood glucose levels on admission $(\mathrm{p}=0.028)$. The 4-month follow-up did not reveal any significant differences in the frequency of MACE in the study groups $(p=0.063)$. The 4-year follow-up revealed a greater incidence of MACE $(\mathrm{p}=0.01)$ and a higher number of diagnosed cases of DM $(\mathrm{p}=0.011)$ in patients with an elevated blood glucose level on admission (Table 2).

Patients with $\mathrm{HbAlc}$ levels $\geq 6.5 \%(48 \mathrm{mmol} / \mathrm{mol})$ were older $(\mathrm{p}=0,004)$, had a higher BMI, i.e. $>30 \mathrm{~kg} / \mathrm{m}^{2}(\mathrm{p}=0.019)$, as well as lower left ventricular ejection fraction $(\mathrm{p}=0,003)$ compared to individuals with $\mathrm{HbAlc}$ levels $<6.5 \%$ (48 $\mathrm{mmol} / \mathrm{mol})$. ECG analysis revealed no significant differences between the study participants; sum STR immediately after PCI, sum STR 60 minutes after PCI, sum STR 24h after PCI, enzymatic analysis; CK i CK-MB, or angiography; TIMI prior to PCI, TIMI after PCI, TMPG (TIMI Myocardial Perfusion Grade), Rentrop. The incidence of MACE in the 4-month follow-up and the 4-year follow-up was comparable in the study population (Table 3 ). 
Andres M (2020) The significance of dynamics of ST segment changes when assessing the effectiveness of mechanical reperfusion of the myocardium in hyperglycaemic patients with acute myocardial infarction with persistent ST-segment elevation

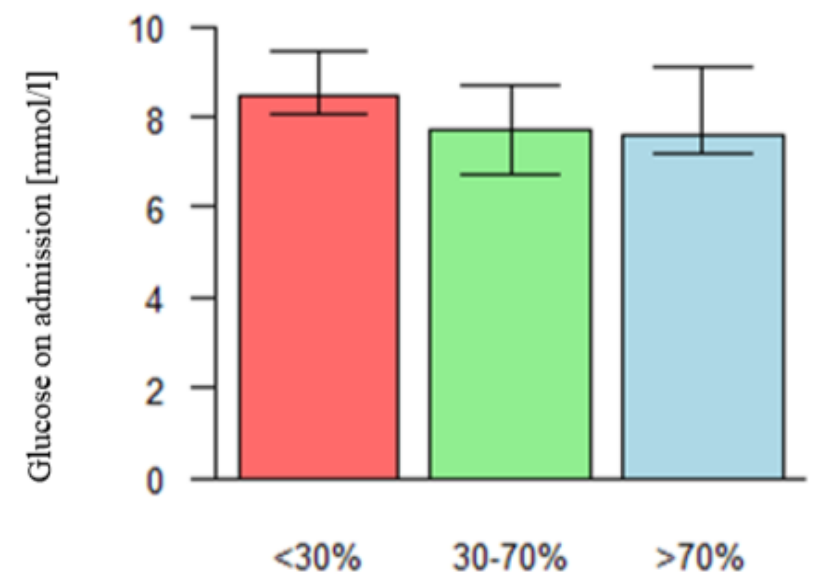

effectiveness of reperfusion after the procedure PCI [\%]

Figure 1. An assessment of the effectiveness of reperfusion based on an analysis of the degree of ST segment elevation resolution in an ECG recording [\%], performed immediately after PCI taking into account absolute blood glucose level on admission [mmol/l] in patients with acute myocardial infarction treated with primary coronary angioplasty. Red bar - a group of patients with ST segment elevation with the degree of resolution on ECG performed immediately after PCI lower than $30 \%$. Green bar - a group of patients with ST segment elevation with the degree of resolution on ECG performed immediately after PCI about 30-70\%. Blue bar - a group of patients with ST segment elevation with the degree of resolution on ECG performed immediately after PCI more than $70 \%$.

Table 1. Clinical characteristics of patients treated with PCI in an acute phase of myocardial infarction with chronic ST segment elevation, depending on the blood glucose level on admission and the HbAlc level.

\begin{tabular}{|c|c|c|c|c|c|c|c|c|}
\hline & Number (n) & $\begin{array}{c}\text { Glc on admission } \\
7.8 \mathrm{mmol} / \mathrm{l}\end{array}$ & Present & $p$ value & Number (n) & HbA1c $6.5 \%$ & Present & $p$ value \\
\hline \multirow{2}{*}{$\begin{array}{c}\text { Arterial } \\
\text { hypertension }\end{array}$} & 46 & $<$ & $22(47.8 \%)$ & \multirow{2}{*}{0.296} & 71 & $<$ & $36(50.7 \%)$ & \multirow{2}{*}{0.366} \\
\hline & 46 & $\geq$ & $27(58.7 \%)$ & & 21 & $\geq$ & $13(61.9 \%)$ & \\
\hline \multirow{2}{*}{$\begin{array}{c}\text { Lipid metabolism } \\
\text { disorders }\end{array}$} & 46 & $<$ & $28(60.9 \%)$ & \multirow{2}{*}{0.832} & 71 & $<$ & $42(59.2 \%)$ & \multirow{2}{*}{0.821} \\
\hline & 46 & $\geq$ & $27(58.7 \%)$ & & 21 & $\geq$ & $13(61.9 \%)$ & \\
\hline \multirow{2}{*}{$\mathrm{BMI} \geq 30,0$} & 46 & $<$ & $8(17.4 \%)$ & \multirow{2}{*}{0.343} & 71 & $<$ & $25(35.2 \%)$ & \multirow{2}{*}{0.019} \\
\hline & 46 & $\geq$ & $11(23.1 \%)$ & & 21 & $\geq$ & $12(57.1 \%)$ & \\
\hline \multirow{2}{*}{ Tobacco addiction } & 46 & $<$ & $30(65.2 \%)$ & \multirow{2}{*}{0.204} & 71 & $<$ & $45(63.4 \%)$ & \multirow{2}{*}{0.093} \\
\hline & 46 & $\geq$ & $24(52.2 \%)$ & & 21 & $\geq$ & $9(42.9 \%)$ & \\
\hline \multirow{2}{*}{$\begin{array}{l}\text { CAD at family } \\
\text { history }\end{array}$} & 46 & $<$ & $14(30.4 \%)$ & \multirow{2}{*}{0.482} & 71 & $<$ & $20(28.2 \%)$ & \multirow{2}{*}{0.693} \\
\hline & 46 & $\geq$ & $11(23.9 \%)$ & & 21 & $\geq$ & $5(23.8 \%)$ & \\
\hline \multirow{2}{*}{ Kidney diseases } & 46 & $<$ & $2(4.3 \%)$ & \multirow[b]{2}{*}{ - } & 71 & $<$ & $2(2.8 \%)$ & \multirow{2}{*}{ - } \\
\hline & 46 & $\geq$ & $3(6.5 \%)$ & & 21 & $\geq$ & $3(14.2 \%)$ & \\
\hline \multirow{2}{*}{ Thyroid diseases } & 46 & $<$ & $4(8.7 \%)$ & \multirow{2}{*}{ - } & 71 & $<$ & $6(8.5 \%)$ & \multirow{2}{*}{-} \\
\hline & 46 & $\geq$ & $4(8.7 \%)$ & & 21 & $\geq$ & $2(9.5 \%)$ & \\
\hline \multirow{2}{*}{ A history of CAD } & 46 & $<$ & $12(26.1 \%)$ & \multirow{2}{*}{0.203} & 71 & $<$ & $14(19.7 \%)$ & \multirow{2}{*}{0.313} \\
\hline & 46 & $\geq$ & $9(19.6 \%)$ & & 21 & $\geq$ & $7(33.3 \%)$ & \\
\hline \multirow{2}{*}{$\begin{array}{l}\text { State after } \\
\text { myocardial } \\
\text { infarction }\end{array}$} & 46 & $<$ & $2(4.3 \%)$ & \multirow{2}{*}{0.456} & 71 & $<$ & $6(8.5 \%)$ & \multirow{2}{*}{0.33} \\
\hline & 46 & $\geq$ & $5(10.9 \%)$ & & 21 & $\geq$ & $1(4,8 \%)$ & \\
\hline
\end{tabular}

Table 2. The occurrence of adverse cardiovascular events in 4-month and 4-year follow-ups of patients treated with PCI in the acute phase of myocardial infarction with persistent ST segment elevation depending on glucose level on admission

\begin{tabular}{|c|c|c|c|c|}
\hline \multirow{2}{*}{$\begin{array}{c}\text { Glc on admission } \\
\text { MACE }\end{array}$} & \multicolumn{2}{|c|}{$<7.8 \mathrm{mmol} / \mathrm{L} \geq 7.8 \mathrm{mmol} / \mathrm{L}$} & \multicolumn{2}{|c|}{$<7.8 \mathrm{mmol} / \mathrm{L} \geq 7.8 \mathrm{mmol} / \mathrm{L}$} \\
\hline & after 4 months & $\mathrm{p}$ value & after 4 years & $\mathrm{p}$ value \\
\hline In Total & $3(6.9 \%)$ vs. $9(24.3 \%)$ & 0.0633 & $11(23.9 \%)$ vs. $23(50 \%)$ & 0.01 \\
\hline Death & $1(2.1 \%)$ vs. $1(2.1 \%)$ & & $2(4.3 \%) v s .4(8.7 \%)$ & \\
\hline Cardiac death & $0 v s .1(2.1 \%)$ & & $1(2.1 \%) v s .2(4.3 \%)$ & \\
\hline Myocardial infarction & 0 vs. $2(4.3 \%)$ & & $3(6.5 \%) v s .8(7.4 \%)$ & \\
\hline $\mathrm{PCI} / \mathrm{CABG}$ & $1(2.1 \%)$ vs $4(8.7 \%)$ & & $4(8.7 \%)$ vs. $9(9.6 \%)$ & \\
\hline Hospitalisation due to $\mathrm{CHF}$ & $1(2.1 \%)$ vs $2(4.3 \%)$ & & $1(2.1 \%) v s .2(4.3 \%)$ & \\
\hline Stroke & 0 & & $1(2.1 \%) v s .0$ & \\
\hline
\end{tabular}


Andres M (2020) The significance of dynamics of ST segment changes when assessing the effectiveness of mechanical reperfusion of the myocardium in hyperglycaemic patients with acute myocardial infarction with persistent ST-segment elevation

Table 3. The occurrence of adverse cardiovascular events in 4-month and 4-year follow-ups of patients treated with PCI in the acute phase of myocardial infarction with persistent ST segment elevation depending on $\mathrm{HbA} 1 \mathrm{c}$ level.

\begin{tabular}{|c|c|c|c|c|}
\hline HbA1c level & $<6,5 \%$ vs. $\geq 6,5 \%$ & & $<6,5 \% \geq 6,5 \%$ & \\
\hline MACE & after 4 months & $\mathrm{p}$ value & after 4 years & $\mathrm{p}$ value \\
\hline In Total & $8(11.3 \%)$ vs. $4(19.0 \%)$ & 0.69 & $23(32.4 \%)$ vs. $11(52.4 \%)$ & 0.387 \\
\hline Death & $1(1.4 \%)$ vs. $1(4.8 \%)$ & & $3(4.2 \%)$ vs. $3(14.3 \%)$ & \\
\hline Including cardiac & $1(1,4 \%) v s .0$ & & $1(1.4 \%)$ vs. $2(9.5 \%)$ & \\
\hline Myocardial infarction & $1(1,4 \%)$ vs. $1(4.8 \%)$ & & $7(9.9 \%)$ vs. $4(19.0 \%)$ & \\
\hline $\mathrm{PCI} / \mathrm{CABG} 1(2.1 \%)$ vs $4(8.7 \%)$ & $3(4.2 \%)$ vs. $2(9.5 \%)$ & & $9(12.7 \%)$ vs. $4(19.0 \%)$ & \\
\hline Hospitalisation due to $\mathrm{CHF}$ & $1(1.4 \%)$ vs. $2(9.5 \%)$ & & $3(4.2 \%) v s .0$ & \\
\hline Stroke & 0 & & $1(1.4 \%) v s .0$ & \\
\hline
\end{tabular}

\section{Discussion}

The aim of the study was to assess the dynamics of changes in the ST segment recorded in electrocardiograms of STEMI patients with concomitant hyperglycaemia compared with persons with normoglycemia treated with coronary angioplasty as well as determine this parameter when assessing reperfusion effectiveness. A significant difference in degrees of ST segment elevation resolution was only evident in electrocardiograms taken immediately after PCI procedure, and concerned the group with lower blood glucose levels on admission. In subsequent measurements (60 minutes and 24 hours after coronary angioplasty), this trend in ST segment elevation resolution continued, although the differences between the study groups were not statistically significant. Similar dependencies were not detectable when assessing the sum STR indicator in patients divided into groups taking into account glycated haemoglobin levels. No statistically significant changes were observed in terms of ST segment elevation resolution in the electrocardiograms, independently of the measurement they were based on.

An angiographic analysis revealed no differences in the flow speed of the contrast agent in the perimeter of the coronary arteries in patients both prior to and following a PCI procedure. This can be explained by the fact that perfusion disorders at the myocardium level observed in an ECG may also occur in spite of an infarct-related artery being effectively reperfused (TIMI 3 ). On the other hand, the absence of optimal flow in the epicardial vessel significantly reduces the likelihood of normal tissue perfusion. The literature includes proof that primary coronary angioplasty resulting in a score of less than TIMI 3 is associated with a poorer long-term prognosis $[15,16]$. The results of studies analysing the impact of reactive hyperglycaemia on the final effect of the PCI procedure are well known. There is evidence that the higher the glucose values observed on admission, the greater the likelihood of slower inflow in coronary vessels - cTFC $\geq 28[17,18]$. In my own study I observed a similar trend between different groups of patients taking into account the blood glucose level on admission, although the differences were not statistically significant. Patients with lower blood glucose values on admission had a higher proportion of TIMI 3 scores and a lower rate of suboptimal results (TIMI 1 and TIMI 2) both prior to and following a coronary revascularization procedure. When treating patients with acute myocardial infarction and persistent ST segment elevation it is essential not only to restore normal flow in the infarct-related artery, but most importantly to correct arterial microcirculation, since impaired tissue perfusion can continue even despite reperfusion of the epicardial section of the artery [19]. An assessment of tissue perfusion (TMPG) revealed no significant differences between the groups. A number of papers have been published confirming that normal perfusion depends on the glycaemia level measured on admission [20,21]. In their own study Chi et al. demonstrated that the higher the level of reactive hyperglycaemia, the worse the outcome compared with TMPG 3, which also had a negative effect on the long-term prognosis [20]. In another publication a strong correlation was observed between higher TMPG grades and the occurrence of optimal flow through infarct-related arteries (TIMI 3 ) and lower values on the cTFC scale [22]. The same study also noted a higher 30-day mortality in individuals with lower TMPG grades, even with concomitant normal flow through coronary artery (TIMI 3 ). In the present study the discrepancies observed in assessments of myocardium tissue perfusion between the sum STR indicator and the TMPG scale, may be due to inaccurate angiographic measurements. Estimating the incidence and timing of image fading in an invasive test is difficult to assess and requires great experience. This may be an additional argument in favour of electrocardiographic analysis.

The study also noted that in patients with reactive hyperglycaemia the degree of ST segment elevation resolution, as an expression of the effectiveness of myocardial reperfusion following coronary angioplasty, was lower than in people with baseline normoglycemia. The slower dynamic in the ST segment in patients with higher blood glucose on admission was especially evident in the electrocardiographic recording made immediately after the PCI procedure. Thus, in order to detect essential differences, ECG recordings should be taken of patients with acute myocardial infarction as early as possible following reperfusion of the infarct-related artery. Deferring or delaying electrocardiography after a PCI procedure may undermine the significance of the sum STR indicator. There is then the risk of losing an important prognostic marker.

Based on indicators of acute and chronic hyperglycaemia, cardiovascular risk was assessed for each of the parameters separately, but attention was also paid to all possible combinations. Three subgroups were formed. The largest group was made up of patients with low HbA1c levels and a low blood glucose level on admission. The smallest subgroup comprised patients with higher HbAlc levels and a lower blood glucose level on admission. The study identified significant differences between the subgroups with regard to the mean values of released myocardial necrotic enzymes in successive measurements. In a subgroup with higher blood glucose levels on admission as well as lower HbAlc levels greater enzymatic heart muscle damage was observed in the first 48 hours of hospitalization together with a much higher frequency of adverse cardiovascular events, both in the 4-month followup and the 4-year follow-up. Similar results were observed in other studies. In a study conducted by Liu et al., 4793 patients with myocardial infarction (STEMI) were divided with respect to their HbAlc results and blood glucose levels on admission, and it was found that the group with high blood glucose levels and $\mathrm{HbAlc}<6.5 \%$ (48 $\mathrm{mmol} / \mathrm{mol}$ ) had a higher mortality rate and a high risk of serious cardiovascular events [23]. Another study drew attention to the fact that concomitant reactive hyperglycaemia and high glycated haemoglobin have a negative impact on a patient's long-term prognosis [24]. It ought to be remembered, 
Andres M (2020) The significance of dynamics of ST segment changes when assessing the effectiveness of mechanical reperfusion of the myocardium in hyperglycaemic patients with acute myocardial infarction with persistent ST-segment elevation

however, that both parameters reflect different patient populations. Most probably due to different pathomechanisms the impact on the long-term prognosis is also different. It was observed that reactive hyperglycaemia has a clearer impact on cardiovascular risk in patients with no history of diabetes than in people diagnosed with the disease [25]. The causes of this mechanism are not exactly known. It is very possible that they result from a greater accumulation of concomitant risk factors of atherosclerosis in advanced diabetes which mutually act upon one another. In such a case the role of hyperglycaemia itself as an individual marker loses its statistical power and undergoes partial dilution.

\section{Conclusion}

In conclusion, a high blood glucose level on admission has an impact on myocardium reperfusion in patients with developing acute myocardial infarction. An increase in blood glucose was shown to be accompanied by greater damage to the microcirculation. This correlation is reflected in the incomplete resolution of ST segment elevation in ECG recordings taken directly after PCI procedures as well as in the greater concentration of myocardial necrotic markers (creatine kinase and its $\mathrm{MB}$ fraction) during the first days of hospitalization in patients with reactive hyperglycaemia equal to or higher than 7.8 $\mathrm{mmol} / \mathrm{L}$. No differences were noted between the study participants in terms of the TIMI scale. This means that ischemic changes in ECG recordings, indicating perfusion disturbances at the myocardium level, may still be observed despite restoration of normal blood flow in epicardial vessels. Microcirculation damage may also increase the risk of cardiovascular events in cases where reactive hyperglycaemia has been diagnosed, especially in patients with an HbAlc level lower than $6.5 \%(48 \mathrm{mmol} / \mathrm{mol})$.

\section{References}

1. Rydén L, Grant PJ, Anker SD, Berne C, Cosentino F, et al. (2013) ESC Guidelines on diabetes, pre-diabetes and cardiovascular diseases developed in collaboration with the EASD: the Task Force on diabetes, pre-diabetes, and cardiovascular diseases of the European Society of Cardiology (ESC) and developed in collaboration with the European Association for the Study of Diabetes (EASD). Eur Heart J 34: 3035-3087. [Crossref]

2. Bartnik M, Ryden L, Ferrari R, Malmberg K, Pyörälä K, et al. (2004) The prevalence of abnormal glucose regulation in patients with coronary artery disease across Europe. The Euro Heart Survey on diabetes and the heart. Eur Heart J 25: 1880-1890.

3. Sanjuán R, Núñez J, Blasco ML, Miñana G, Martínez-Maicas H, et al. (2011) Prognostic implications of stress hyperglycemia in acute ST elevation myocardial infarction. Prospective observational study. Rev Esc Cardiol 64: 201-207. [Crossref]

4. David LA, Grosu AA (2013) Abnormal glucose tolerance and long-term prognosis in patients with acute myocardial infarction. Kardiologiia 53: 15-20. [Crossref]

5. Mazurek M, Kowalczyk J, Lenarczyk R, Zielinska T, Sedkowska A, et al. (2012) The prognostic value of different glucose abnormalities in patients with acute myocardial infarction treated invasively. Cardiovasc Diabetol 11: 78. [Crossref]

6. Norhammar A, Tenerz A, Nilsson G, Hamsten A, Efendíc S, et al. (2002) Glucose metabolism in patients with acute myocardial infarction and no previous diagnosis of diabetes mellitus: a prospective study. Lancet 359: 2140-2144. [Crossref]

7. Bellodi G, Manicardi V, Malavsi V, Veneri L, Bernini G, et al. (1989) Hyperglycaemia and prognosis of acute myocardial infarction in patients without diabetes mellitus. $\mathrm{Am}$ $J$ Cardiol 64: 885-888. [Crossref]
8. Wahab NN, Cowden EA, Pearce NJ, Gardner MJ, Merry H, et al. (2002) Is blood glucose an independent predictor of mortality in acute myocardial infarction in the thrombolytic era? J Am Coll Cardiol 40: 1748-1754. [Crossref]

9. Kosiborod M, Rathore SS, Inzucchi SE, Masoudi FA, Wang Y, et al. (2005) Admission glucose and mortality in elderly patients hospitalized with acute myocardial infarction implications for patients with and without recognized diabetes. Circulation 111: 30783086. [Crossref]

10. Tomaszuk Kazberuk A, Kożuch M, Małyszko J, Bachórzewska Gajewska H, Dobrzycki S, et al. (2012) What level of hyperglycaemia on admission indicates a poor prognosis in patients with myocardial infarction treated invasively? Kardiol Pol 70: 564-572. [Crossref]

11. Capes SE, Hunt D, Malmberg K, Gerstein HC (2000) Stress hyperglycaemia and increased risk of death after myocardial infarction in patients with and without diabetes: a systematic overview. Lancet 355: 773-778. [Crossref]

12. Marik PE, Bellomo R (2013) Stress hyperglycemia: an essential survival response! Crit Care 17: 305. [Crossref]

13. de Lemos JA, Braunwald E (2001) ST segment resolution as a tool for assessing the efficacy of reperfusion therapy. J Am Coll Cardiol 38: 1283-1294. [Crossref]

14. Schröder R, Dissmann R, Brüggemann T, Wegscheider K, Linderer T, et al. (1994) Extent of early ST segment elevation resolution: a simple but strong predictor of outcome in patients with acute myocardial infarction. J Am Coll Cardiol 24: 384-391. [Crossref]

15. Olszowska M, Tracz W, Kostkiewicz M, Podolec P (2008) Predictive factors of myocardial reperfusion in patients with anterior wall acute myocardial infarction. Cardiol J 15: 57-62. [Crossref]

16. Cura FA, L'Allier PL, Kapadia SR, Houghtaling PL, Dipaola LM, et al. (2001) Predictors and prognosis of suboptimal coronary blood flow after primary coronary angioplasty in patients with acute myocardial infarction. Am J Cardiol 88: 124-128. [Crossref]

17. Eshraghi A, Talasaz AH, Salamzadeh J, Bahremand M, Salarifar M, et al. (2014) Study of the possible medical and medication explanatory factors of angiographic outcomes in patients with acute ST elevation myocardial infarction undergoing primary percutaneous intervention. Adv Biomed Res 3: 186. [Crossref]

18. Yildiz A, Arat-Ozkan A, Kocas C, Abaci O, Coskun U, et al. (2012) Admission hyperglycemia and TIMI frame count in primary percutaneous coronary intervention. Angiology 63: 325-329. [Crossref]

19. Roe MT, Ohman EM, Maas AC, Christenson RH, Mahaffey KW, et al. (2001) Shifting the open-artery hypothesis downstream: the quest for optimal reperfusion. $J$ Am Coll Cardiol 37: 9-18. [Crossref]

20. Chi HJ, Zhang DP, Yang XC, Yang ZS, Xu Y (2009) Hyperglycemia at admission and outcome in elderly patients with acute ST segment elevation myocardial infarction underwent primary percutaneous coronary intervention. Zhonghua Xin Xue Guan Bing Za Zhi 37: 595-598. [Crossref]

21. Shen XH, Jia SQ, Li HW (2006) The influence of admission glucose on epicardial and microvascular flow after primary angioplasty. Chin Med J (Engl) 119: 95-102. [Crossref]

22. Gibson CM, Cannon CP, Murphy SA, Ryan KA, Mesley R, et al. (2000) Relationship of TIMI myocardial perfusion grade to mortality after administration of thrombolytic drugs. Circulation 101: 125-130. [Crossref]

23. Liu Y, Yang YM, Zhu J, Tan HQ, Liang Y, et al. (2012) Haemoglobin A(1c), acute hyperglycaemia and short-term prognosis in patients without diabetes following acute ST-segment elevation myocardial infarction. Diabet Med 29: 1493-1500. [Crossref]

24. Guo CY, Shen LH, Li HW, Teng YX, Zhao SM (2009) Relation of Hemoglobin A1c to myocardial acoustic densitometry and left ventricular diastolic function in patients with Type 2 diabetes mellitus and without evident heart disease. Diabetes Res Clin Pract 83: 365-370. [Crossref]

25. Santoro GM, Valenti R, Buonamici P, Bolognese L, Cerisano G, et al. (1998) Relation between ST segment changes and myocardial perfusion evaluated by myocardial contrast echocardiography in patients with acute myocardial infarction treated with direct angioplasty. Am J Cardiol 82: 932-937. [Crossref]

Copyright: (C2020 Andres M. This is an open-access article distributed under the terms of the Creative Commons Attribution License, which permits unrestricted use, distribution, and reproduction in any medium, provided the original author and source are credited. 